\title{
Effect of Demographic Factors on E-Learning Effectiveness in A Higher Learning Institution in Malaysia
}

\author{
Md. Aminul Islam \\ School of Business Innovation and Technopreneurship, University Malaysia Perlis, Malaysia \\ Noor Asliza Abdul Rahim \\ Center for Communication Skills and Entrepreneurship, University Malaysia Perlis, Malaysia \\ Tan Chee Liang \\ School of Graduate Studies, Olympia College Penang, Malaysia \\ Hasina Momtaz \\ School of Business Innovation and Technopreneurship, University Malaysia Perlis, Malaysia
}

\begin{abstract}
This research attempted to find out the effect of demographic factors on the effectiveness of the e-learning system in a higher learning Institution. The students from this institution were randomly selected in order to evaluate the effectiveness of learning system in student's learning process. The primary data source is the questionnaires that were distributed to the students. Data were then analyzed using SPSS. Findings confirmed that age, program of study and level of education has significant affect on the effectiveness of E-learning. Therefore it is recommended that a careful review of delivery methods should be undertaken before starting of every intake taking into consideration of diverse background of students. Comparisons should be made between the effectiveness of e-learning and traditional learning methods via students' assessment after each session of lecture. It is also recommended that the institution to look into the issue of familiarity of with online learning technology amongst students before introducing the e-learning system to assess whether student are comfortable with the online learning tools.
\end{abstract}

Keywords: E-learning, Effectiveness of e-learning, Demographic factors, Higher learning institution, Malaysia

\section{Introduction}

In the past, computers are very complicated machine and not many people know what they are nor do they want to go near these machines, yet they are aware that computers do lots of wonders, and simplify complicatedness and simplicity. It all stated back in year 1936 where computers are free to be programmable and it went back to the 40s when John Atanasoff and Clifford Berry (1942) began computing business and like any other new emerging technologies or business, it's never easy. All the way to the 50s, computers began to be used commercially and mid $50 \mathrm{~s}$, the very first successful high level programming language, the well-known FORTRAN was born and not forgetting the magnetic ink character recognition (MICR) was introduced to the banking industry. 60s came by when more devices are being brought into the Information Technology era and also the introduction of the Internet. More and more technologies come in along the way such as the Internet, networking and word processors in the 70s. The Graphical User Interface came knocking on the door in the 80s and today, we have more new technologies emerging so fast. The nest sub-topics will be covering the trend of technology and also how these new technologies penetrate into the teaching world.

Technologies have been changing and improved over the years and more and more people are having computers in their homes. With these technologies, it made computers a much easier machine to be used and it has become a lot of people's best friend these days. With the help from the Internet, generating knowledge, gathering of information, expanding network in various aspects, to name a few are now in our finger tips and is just a click away. We are all well exposed to the world out there and without going over to various places to learn more things as in the past, all we need now are a set of computer, modem and phone lines, everything is hooked up and less money are required.

Many education organizations today practices the electronically learning method known as the e-learning that used the CD ROM, Internet, video conferencing, satellite transmissions, and etc. as tolls to deliver the knowledge across to the learners. Internet is still the most frequent used method as it covers a wider area and this is being used in both the public and private education system. The Internet and education world combination had a great influence among the students in schools, colleges and universities. The working adults in the corporate world are never being left out in the learning circle. The Internet had became the driveway for all learners to drive through to access the information that interest them and with the on-line discussion groups and multimedia help, it create an advantage 
over learning for them that learning never came to an end. Information is now available at the finger tips on all people's category so long they have the required set up. The education providers need to invest some amount of money in order to set up the necessary infrastructure, hardware, software, human resources to do the set up and necessary development to start the ball rolling. However, the return on investment is always on the positive mark as this will attract more students from all over the world to engage into your organization especially if the provider has a good data warehouse to store as much information as possible for the learners to pool from for their research or learning materials. Flexibility is what learners are looking for these days and fast access as well as easy access attracts more learners. Facts at the finger tips allows them to work their way through to get the necessary information and the Internet is the answer, therefore, e-learning is the solution to this.

According to Opinion Research Corporation (2000) revealed that 54 percent who believe that college courses offered via the Internet are the future of higher education. The study also found that 32 percent of respondents agreed to take the course through the Internet rather than go to a traditional classroom. Another 53 percent of respondents said that the biggest benefit of taking courses online was the ability to work from home, while 19 percent cited that time saved from not having time to commute. Due to a lot of advantage sector the e-learning program as one of the learning methods to enhance learners' knowledge and skills.

However, the above statements are such a promising concept but, are this really good and bright picture that an organization could paint on? Many question regarding the effectiveness of e-learning has surfaced. Is e-learning program able to provide an effective way of delivery knowledge? Does peer to peer interaction is well supported in e-learning? Did the learner feel that they leaned anything from the e-learning program? How do the learners rate the quality and effectiveness of their e-learning program? To what extent do the learners are satisfied with the online learning experience provided by the e-learning? What do learners think about the e-learning courses they have taken in term of course content, layout, language, graphics, animation of technology holds for learners' achievement is realized? To effectively deploy e-learning program for the learners, the educators or trainers need to integrate testing and assessment tolls throughout the learning process. It is important to understand the effectiveness of this innovative and advance-learning method in many related leaning areas. Therefore, a study on the effect of demographic factors on e-learning effectiveness is an essential element to assess the impact of the e-learning on the learners.

\section{Literature Review}

The introduction of new computing technology is now widely adopted throughout the world for storing, keeping, searching and gathering information and records, constructing knowledge, performing simulations to develop knowledge base, skills, distance learning, and global collaboration for lifelong learning and work. The power of emerging computing technologies has indeed transforming our every aspect in new ways that are enabled by powerful computing technologies to run and managing their business processes more efficiently, boost customer satisfaction and improve their performance. With the advent of the advanced and innovative computing technologies, it is not only having impact on our live but also changes in the way of learning process in learning environments. For example, educators use of the Internet technologies as an online learning ways for teaching and learning, in which enabling learners to receive and interact with educational materials and resources through internet, as well as engaging with teachers and peers in ways that previously may have been impossible (Kirkwood, 2001)

Studies (i.e., Cohen, 2001) have indicated that the use of technology has an effect on all aspects of teaching and learning. When educators integrated technology into the lesson, it required new learning approaches to the curriculum because of the ability to look at and explore information in new ways. Moreover, some studies have emphasized that technology can help by allowing learners to take a more active role in their learning through different instructional modes or methods (Kussmaul and Dunn, 1996). Dewar and Whittington (2000) commented that the new technologies provide opportunities for creating learning environments that enhance learner learning and achievement. However, inappropriate uses of technology can become ineffective learning. Thus it is important to understand what technology is and how to use it and, most importantly, is comfortable using it (Smolin and Lawless, 2003).

Research findings showed that the impact of emerging computing technologies bring tremendous advantages in learning environments. For example, O' Conner (1997) reported that electronic message boards and forums allow teachers and students to post information, discussions. Comments, problems and questions etc. can respond too? Also, technology offers convenience, flexible and powerful new ways to gaining access to a universe of the informational resources at anywhere and anytime, for example online library system. O' Connor (1997) also highlighted that electronic communication such as e-mail and interactive distance learning, and the Internet such as World Wide Web site enable to build the strong and close relationship with the scholar's community and join groups 
where expert share ideas. Similarly, Thornburg (1997) looked at ways in which interactive multimedia presentation with the audio, video, graphics and animation could enrich, extend or facilitate learning, increase productivity and promote creativity. Stepp-Greany (2002) also noted that technology helps incapable students by "redistributing teacher and classmate attention so that incapable students can become more active participants in the class" A review of studies carried out by Stepp-Greany (2002) reported that there are a number of benefits for students related to the general use of technology in the classroom. These include increase motivation, more in higher-order thinking skills and better recall.

As evidenced by varieties of researchers, the presence of computer technology has increased dramatically and become an important instrument in learning environments because it's not just offers powerful pedagogical tools but also extensions of human capabilities and contexts for social interactions supporting learning.

\subsection{The Evolution and Transformation of Traditional learning method to E-learning Method in Education Sector}

In the traditional methods of learning, it involves instructors, face-to-face traditional classroom with whiteboard and blackboard, and together with transparencies and text books for delivery information to learners have to attend classes based on a fixed schedule and each class session is for a fixed period of time. The learners have a textbook or any other reference books containing information on the particular subject. There is an instructor presents in the classroom, and the role of instructors is to teach and assist learners acquire knowledge and academic skills necessary for their success in higher education. The learners will listen to an instructor; write down the main points and any important facts, opinions and examples. The traditional learning mode is contributed to two-way communication classroom because there is an interaction between instructors and learners. Therefore, the learners may feel more comfortable when they can communicate immediately and interact directly with their instructors about any difficulties they faced.

As the natural of rapid evolution of technology, using traditional methods of learning may quickly become outdated and ineffective learning methods as learners cannot adapt their learning process to fit today's complex work environment even though traditional learning methods still work best and used in many market segment areas. For this reason, people must be able to learn from new innovative leaning methods in order to stay ahead in the technology race and not to lad behind.

According to Cohen (1997) introducing the technology into classrooms has made it possible for the learners to lean up four times more effective than traditional education approaches. Charp and Sylvia (2003) related that learning incorporates to technology-based within the students' learning process and the teachers' delivery process is more effective than traditional classroom. They also emphasized that the technology-based education can improve learning and teaching experiences, increase interaction with others who are geographically remote and also provide richer communication opportunities.

Pete Maurer (2001) recognizes that the purpose of providing the e-learning to schools is to improve student learning outcome and achievement and also other educational outcomes, and is not to provide state-of-the-art equipment for its own sake. However, he also emphasizes that e-learning can be effective in incrementing student's achievement, but hits effectiveness depends upon how and if the e-learning is used properly and correctly by teachers and students and not depends whether a classroom has the latest technological instruments and software available. He implicates that the educational systems should embrace and incorporating the learning environment and its technology into classroom and it is essential that they teach the students of tomorrow with the tools available today. Through an examination of e-learning, one can see the important the technology plays in an educational environment.

\subsection{Definition of E-learning}

Electronic leaning or so-called E-learning is an advanced technology-based learning delivering educational program or training electronically. E-learning is an extremely flexible education method that can fit into any schedule and emphasized on "Anytime, Anywhere, Anyone". E-learning increases the flexibility in the transferability and sharing of knowledge because learners can learn from anywhere and at any time they want. Introduction of this new method has greatly eliminated time, travel and attendance constraints.

Dormant Woodall (2002) defined e-learning as "experience" learning that uses technology to design, deliver, select, administer, support and extend the learning process.

Kapp (2003) defined e-learning as "the delivery of training materials, information and connect directly to an employee's computer desktop by taking advantage of Web browser technology to purposefully change behavior or attitude. Hall and snider (2000) defines e-learning as the process of learning via computers over Internet and intranets and referred to as web-based training, online training, distributed learning or technology for learning. 
Urdan and Weggan (2000) defined e-learning as "the delivery of content via all electronic media, including the Internet, satellite broadcast, intranets, audio or video tape, and interactive TV. They also emphasized that e-learning covers a wide set of applications and processes, including web-based learning, computer-based learning, virtual classrooms, and digital collaborations.

E-learning material consists of graphics, text, video, audio, animation or virtual environment and text materials can be delivered in many forms. For example, the learning material can be presented through electronic chatting, interaction through videoconference, discussion through e-mail, simulations, online quizzes or tests or assignments. E-learning can be in CD-ROM based, network-based, Intranet or Extranet-based, Internet-based and so on. Learner has the flexibility to choose the form and channel that most suite their preference.

\subsection{Comparison between the Traditional Classroom Learning and Electronic Learning}

Learning is what everybody needs in order to keep themselves in touch and updated with the fast growing world and like in the old saying, there's no end to learning. The practice that we've been exercising over centuries is classroom learning style whereby we attend classes with books, lecture notes or other hard copy materials with us where we will see a lecturer or teacher in front of us explaining to us about the content of studies and this happens till today. With the advancement of technology in today's World, a lot of things have become electronically or virtually and this happens to the education circle whereby we've been introduced to Electronic Learning or e-learning for short.

Many would be wondering what is this new age game that we've been introduced and what are the differences could it make comparatively to the traditional classroom learning. Some would start thinking that how could a students relate to the lecturer or teacher in the electronic era? E-learning uses CD-ROMs, Internet, Web Portal, E-book, video, audio, animation, etc. to get the materials across to the students. Sure enough, there are more than what is being described here, let's look at the differences between the traditional classroom learning methods.

\subsection{Demographic Factors and the Effectiveness of E-learning}

Currently, literature on the effectiveness of e-learning as an educational intervention already abounds. Aside from educational institutions, many corporations and even non-profit organizations had been adopting this modern tool. Yet, despite this preponderance of data, little inquiry was done as to the demographic factors that could determine the strength of its differential impact on people from diverse backgrounds. This limitation is evident in this brief literature review. Given this context, the following could be reviewed as a humble attempt to contribute to the enlightenment of this subject matter.

\section{Gender}

There was a study providing a correlation between gender and level of learning (Schodt 2005). It was supposed that males, generally, have higher levels of affect than female students in classroom scenarios where instructors used no technology, whereas female students reported higher levels initial affect than male students in classroom scenarios where instructors used moderate amounts of technology (Schrodt 2005). Nonetheless, is was also observed that across genders, continued incremental use of technology would eventually lead to a point to diminishing returns, whereby technology becomes a distraction and students' initial motivation to learn course material suffers (Schrodt 2005 , p.). A recent survey of the demographic picture of e-learners also indicated that males have the upper hand, garnering around $62 \%$ (Mungania, p.3).

\section{Age}

Older people have relatively slower perceptual learning than younger ones (Gilbert 1996). This input could be factored in the designing materials for audiences of varying ages. Mungania (2003), in his description of the e-learning users, asserted that middle-aged people account for the great part of the educational approach's audience, with $80 \%$ of the polled respondents belonging to the lower that 45 years age bracket.

\section{Students' status}

An implication of student status in e-learning is that full-time students who spend more time acquainting with the system naturally have the edge over its part-time students. Other relevant variables include the student's learning profile, such as his study styles and habits preferred learning (whether he is included more on actual interactive classroom discussion or his welcome IT-based educational interventions).

\section{Program of study}

There was no study that directly correlates program of stuffy with the effectiveness of e-learning. However, it could be logically surmised that e-learning would be more useful in the field of IT and engineering subjects. In the corporate set-up, e-learning is finding great use in employee training (Pantazis 2001, p.21). 


\section{Level of education}

In his presentation, Mungania (2003) suggested that e-learning caters to people who have a relatively high degree of academic and professional education. In his backdrop of e-learners, he maintained that $37 \%$ are bachelor's degree holders, $56 \%$ continue studying while in the office, $80 \%$ have been enrolled in no less than ten online courses and that $96 \%$ are intermediate and advanced uses of computer training exposure and that $87 \%$ registered warm acceptance of the modern learning approach.

\section{Race}

In his case study, Dimitrov (1999) posited that gender differences in science achievement did not depend on ethnicity (p.445). These ideas have noteworthy value in drafting of an e-learning module, especially for science classes. The conception that racial discrimination, based on socio-economic stratification, could be extended in the realm of e-learning was never substantiated by research. However, Mungania (2003) pointed that $49 \%$ of e-learners are generally of European descent, meaning "Caucasian" or "white". To circumvent the so-called digital divide, between those who have access to the technology and those segments of society who cannot, governments of industrialized countries had enacted laws to strengthen their over-all Information and Communication technology (ICT) frameworks and with respect to e-learning, had provided for state-run schools to have these facilities (Eklund, Kay, Lynch 2003).

\section{Marital status}

Information on the effect of this variable to the effectiveness of e-learning is also non-existent and that any linkages that could be thought of are, at best, assumed and lacked academic groundings. Mungania (2003) agreed that it is not a major determinant for e-learning's success.

\section{Employment}

There was an absence in the literature concerning the bond between this demographic factor and the effectiveness of e-learning. One of the finding highlighted by Mungania (2003) in his doctoral dissertation was that $76 \%$ of e-learners had participated in e-learning exercises three years prior. He found out that $34 \%$ of most e-learners did have previous e-learning know-how from a previous company or employer. One could therefore conjecture that the level of effectiveness of e-learning would rest much on how the steering and leading and leading functions would be handled by senior firm executives.

\section{Research methodology}

Data were collected from the higher learning institutes Study Centre via distributed questionnaires. The survey questionnaire was consisted of two sections: section A consisted of items to get demographic information and section B consisted of 9 items to measure the effectiveness of e-learning. Survey questionnaires were distributed to randomly selected students. The reason for the choice of using questionnaires approach as data gathering method for this study is because it is an effective and inexpensive way to gather data from a potential large member of respondents. Often questionnaires allow the researcher to carefully evaluate the findings, and also allow the respondents be more time to carefully think over the questions asked before answering them thereby the quality of the data received will be much better. According to Sekaran (2000), questionnaires are an efficient data collection mechanism where researcher can target his/her questionnaires to the more informed respondent and obtain better quality in the data.

Based on research problem and literature review discussed in the preceding sections, a total of 6 hypotheses statements were constructed to test whether the relationships that have been theorized do, in fact, hold true.

The formulated hypotheses for this study are listed as follow:-

$\mathrm{H} 1$ : There is a significant relationship gender and the effectiveness of e-learning.

$\mathrm{H} 2$ : There is a significant relationship between marital status and the effectiveness of e-learning.

H3: There is a significant relationship between race and the effectiveness of e-learning.

H4: There is significant relationship between program of study and the effectiveness of e-learning.

H5: There is significant relationship between level of education and the effectiveness of e-learning.

H6: There is significant relationship between age and the effectiveness of e-learning.

This institution has centres throughout Malaysia such as Kuala Lumpur, Sarawak, Sabah, Kelantan, Penang, Negeri Sembilan and Perak, the Penang Study Center was selected for this study. The targeted population for this study consists of genders, different age group, different background and those registered in different courses at the Penang 
Study Center. The unit of analysis for this study was the individual in which the data were collected from each individual student. A simple random sampling method was used to select the respondents for the study. A sample size of one hundred students was chosen at random for this study and a total number of 100 pre-set questionnaires were distributed randomly to these selected students and 80 questionnaires were successfully collected for further analysis.

\section{Findings}

This section presents the data analysis and findings.

\subsection{Overview of data gathered}

A total of 100 questionnaires were distributed among sampled population and only 80 questionnaires were successfully collected. Therefore, the response rate for this study is $80 \%$. Table 2 illustrates the overview of the sample profile. These 80 questionnaires were used for analysis in the present research. The questionnaire data analyzed using SPSS and the subsequent data analyses were undertaken using statistical approach i.e. One-way ANOVA and t-test.

\subsection{Data Presentation}

The questionnaires used in the present work were designed into two main sections, which comprised demographic characteristics and the dependent variable (effectiveness of E-learning). Section A details a total of eight demographic characteristics, i.e. gender, age, student status, program of study, level of education, race, marital status, and employment.

In this aspect of gender, the gender respondents are divided into two main categories, i.e. male and female. Female students have the highest number, which is more than half of the total respondents (78.8\%). This reveals that there are only $21.3 \%$ of the respondents are male students $(21.3 \%)$. The majority of the respondents are relatively young. Indeed, most of the respondents are from the age group of $21-23$, which takes up $58.8 \%$ of the total respondents. These are then followed by the age group of 18-20 (13.80\%), 24-26 (11.3\%), 30 and above (10.0\%) and finally by the group with the least frequency are from the age of 27-29 (6.3\%).

The student statuses of the respondents are categories into two main groups, i.e. those taking up the full time courses or the part time courses. From the analysis, it may be seen that approximately $78.8 \%$ of the respondents are taking up the full time courses, and the rest of the respondents are taking up the part time courses $(21.3 \%)$. As may be seen from Table 3, the programs of study consist of information technology, business administration, humanities and social sciences, and graduate studies. Out of these courses, the large proportion of the respondents is taking up the business administration, which is $45 \%$. The results also indicate that students who are studying humanities and social sciences constitute $28.8 \%$; information technology (21.3\%) and graduate studies (5\%).

In the level of education, there are relatively large percentage of the respondents are degree holders or currently pursing a degree. This group of respondents consists of $75.0 \%$. The second majority of the respondents have diploma qualifications, which is approximately $21.3 \%$. The respondents with qualifications of advanced/higher/graduate diploma are only 3.8\%. As far as the racial composition is concerned, there are three main races took part in the present research. These include Malay, Chinese and Indian. As depicted in Table 3, Malay students are the majority respondents, which comprised nearly half of the total respondents (46.3\%). This is followd by the Indian students (37.5\%). The Chinses students are the least, which is about 13 students out of the total 80 students (16.3\%) taking part in this study.

In terms of martial status, three major groups participated in the survey, i.e. single, living together and married. The overall findings of the questionnaires reflected that almost all the respondents are single, which is about 77 respondents out of total 80 , meaning that there are estimated to be $88.8 \%$. Both groups of respondents who are living together or are married were equal in size, which have the nearly same percentage of 5\% and $6.3 \%$ for the group of living together and married, respectively. With regards to the respondents' employment, the analysis revealed that there are exactly 22 respondents out of a total 80 respondents (27.5\%) are currently employed, and corresponding there are 58 respondents $(72.5 \%)$ are unemployed.

\subsection{Effect of Demographic factors on the effectiveness of e-learning}

The one-way ANOVA and T-test were employed to identify the effect of demographic factors on the effectiveness of the online learning. One-way measures the mean of one or more groups based upon independent demographic variables. On the other hand, T-test is usually employed to evaluate the difference in the means between two groups. In the present research, one-way ANOVA was used for age, program of study, level of education, race and marital status, whilst T-test used in gender, students status and employed. 
Based on the Oneway ANOVA results, age, program of study and level of education were found to have significant effect on the effectiveness on E-learning. Therefore hypotheses 4, 5 and 6 were substantiated. Race and marital status did not have any effect on the effectiveness of E-learning. The independent sample t-test reveals that male significantly differs from female in respect to the effectiveness of E-learning. Therefore hypothesis 1 was accepted.

\section{Discussion}

Demographic factors such as level of education and gender are major factors in understanding and appreciating e-learning. It is presumed that students with high levels and strong educational back grounds have a broader knowledge on the use of technology and its advantages on gaining scholastic achievement. They are exposed to the latest innovation that technology offers. They are expected to be more computer literate which makes it easy for them to explore the Internet. Also, students with higher level of education tend to update their knowledge and information that can easily be gained thorough e-learning. For example, rather than go to the library to research about a new topic, they just make use of the online library. Hence, e-learning for them is effective.

Results show that gender is a key in appreciating e-learning. A report released in October 1998 by the American Association of University Women (AAUW). Educational Foundational showed that females come to school with less computer experience that males and years later, leaves the same way (Caine \& Weinman, 1999) this concern is a manifestation in the society where a small number of women entering technology fields in college and graduate school. Few women are also observed working in computer-related jobs beyond the data-entry work of a secretary. In a computer class, female students make up only a small percentage. As discussed by Caine and Weinman (1999), in 1996, only $17 \%$ of advanced placement test takers in computer science were females in while the rest were males. Males usually use the computers for programming and problem solving while women tend to use them for word processing alone. In addition, make also have more experience with computers outside of school, which build their self-confidence and positive attitudes about computers.

Thus, men are the ones who will most likely appreciate e-learning and learn things from it since they are more interested in technology. There are no specific studies that may support such speculation but one important finding showed that women prefer working in a group than working alone (www.ecternal.swap.ac.uk). This may imply that women are more comfortable learning in a classroom environment where interaction with the instructor and other students can be experienced.

This study may pave the way for upgrading the methods of instruction being used today. Online learning can be collaborated with the traditional method, which is classroom-based to facilitate teaching. The finding from the present work may provide reference of background knowledge for future studies on investigating the effectiveness of e-learning and its effects on other areas like employment, social work practice and economy.

\section{Implications of finding}

Results of this study show that e-learning is an effective tool in education. Somehow, it has positive effect on the learning process of student. It can actually provide additional and updated knowledge that may not be gained in a classroom-based instruction. The impact of e-learning may be extended to other sectors like in social work.

E-learning offers potential benefits for social workers (www.elfs.org.uk). It offers flexibility since anytime and anywhere it can easily be accessed. It also widens accessibility to learning opportunities through access. Information literacy like related facts on social work, writing and presentation sills can be gained. It also brings an improved motivation and engagement through the new things to be learned. Though e-learning, social workers can easily assess, monitor and record their learning progress. Hence, this will make them aware of the strengths and weakness they have and what they will need to have a strong background in social care.

Realizing the positive effects that e-learning brings, the social work sector may look into the need of improving the training for social workers. E -learning can be incorporated in the above mentioned trainings. The method if properly implemented can be an effective tool to support learning as a collaborative, collective and social experience (www.elfs.org.uk). Furthermore, this study emphasizes the need for the social workers to be computer-literate and interested with the latest advancement in technology. This will somehow enhance their social care knowledge and develop their critical thinking skills that will cultivate their active participation in rendering service to the community they serve (www.elfs.org.uk).

One important result of the study is about the technical barriers that women face. They are regarded as not much interested in learning new technology. This effect may create awareness on the empowerment of women in terms of education and employment. In education, the use of computer and it applications undeniably helps in understanding the lessons and solving numbers related problems. Thus, it is necessary that women are computer-literate to take advantage of the updated information that can be obtained online. Having a strong background in computer education will help them to get a high-paid job. This will also make them competitive individuals in the workforce. 
It is observed that most of the companies now offer a competitive salary to people who are computer-literature and knowledgeable on the different computer applications. This is because most of their jobs are computer-based.

Furthermore, e-learning can somehow address the issue of social injustice, which is usually caused by low educational achievement. People who have low educational level or not educated at all tend to receive an unfair treatment from the society. This is because they are perceived as "useless" since they do not have anything to contribute for the improvement of the society. Therefore, it is important that people acquire knowledge that can easily be accessed through online learning. This will make them well-informed and useful to community.

In general, the results of this study snuggest that resources such as technology should be used to be able to acquire knowledge. E-learning offers benefits to the learners which include students and professional in the easiest and cost-effective way. Moreover, this study indicates that further researches must be don't to be able to establish the applications of the mentioned tool not only in education but also in other sectors, studies about its impact on the issues of empowerment, social justice and discrimination can also ex explored.

\section{Conclusions}

Based on the results the level of education, program of study, age and gender were found to be significant in the effectiveness of e-learning. However race and marital status were found to have no significant effect on the effectiveness of e-learning system. Therefore it is indicated that respondents with higher level of education may have accepted using e-learning tool as a learning program and therefore contribute to the effectiveness of the e-learning system. As far as gender is concerned, there is a significant effect on the effectiveness of e-learning. This is due to the fact that female participants may be more patient that male counterparts, and therefore the female participants may not get agitated easily and so may well be more benefited from the learning program. Thus, gender contributes to the effectiveness of e-learning system.

\section{References}

Charp, Sylvia. (2003). “Online learning in Virtual High School." International Journal of Instructional Media, p.8.

Cohen, V. L. (1997). Learning styles in a technology0rich environment. Journal of Reaserach on Computing in Education, 339-350.

Cohen, V.L (2001). Learning Styles in a Ninth-Grade High school Population. Journal of reaserch on Computing in Education, 33, (4), p.355. Retrieved Febuary 26, 2004, from EBSCO database.

Dewar, T. and Whittington, D. (2000). Online learners and their learning strategies Journal of Educational computing Research, 23 (4). 385-403.

Dimitrov, D. (1999). "Gender differences in Science achievement: Differential effect ability, response format, and strands of learning outcomes", School Science and Mathematics, Vol. 99, Issue 8, p. 445

Dormant Woodall. (2002), "Evaluating E-learning Solution", September 2002 (Online). Available from: http:/www.clomedia.com/content/templates/wp_clo_whitepaper.asp?articleid=36\&zoneid=26.

Eklund, J., Kay, M. and Lynch, H. (2003). "E-learning: emerging issues and key trends (a discussion paper)", Australian National Training Authority, 25 September, (Online) Available from: http://www.flexible learning.net.au/research/2003/elaerning250903final.pdf.

Hall, B. \& Snider, A. (2000). Glossary: The hottest buzz words in the industry. E-Schreiber, D.A., \& Berge, Z. L. (1998).

John Atanasoff \& Clifford Berry. (1942). ABC Computer, "The History of Computers". Who was first in the computing biz is not always as easy as ABC. [Online] Available form: $\mathrm{http}: / /$ inventors.about.com/library/blcoindex.htm.

Kapp, K.M., (2003). “Winning E-learning proposals: The Art of development and delivery”, J. Ross publishing.

Kirkwood. (2001). Teaching and Learning on the World Wide Web, Institute for Interactive Multimedia, Universtiy of Technology, Australia.

Kussmual, C. \& Dunn, J. (1996). Using technology in technology. College Teaching, 44(4), 123. retrieved Febuary 26, 2004, from Academic Search Premier database.

Mungania, P. (2003), “Seven E-learning barriers facing employees: Executive summary of dissertation”, University of Louisville, (Online), Available from: http://www.masie.com/researchgrants/2003/mungania_exec_summary.pdf.

O'Conner, t. (1997). Using learning styles to adapt technology for higher education. [Online] Available form: http://www.indstate.edu/ctl/styles/learning.htm. 
Opinion Reaserach Corporation. (26 July 2000). Education News, Working Adults like Online Education. [Online] Available form: http://www.skymarkgroup.com/industry-news-education.

Pantazis, C. (2002). "Maximizing E-learning to train the $21^{\text {st }}$ century workforce", Public Personnel Management, Vol. 31, Issue 1, P. 21.

Pete Maurer (2001). "Evolution and Revolution in Management: From Organizational Learning to e-Learning", Tampere Polytechnic, Business school.

Schodt, Paul. (2002). "The relationship between organizational identification and Organizational culture: Employee perceptions of culture in a retail sales organization", Communication studies, vol.53 no. 2, p. 189.

Sekaran, U. (2000). "Research methods for business: A skill building approach", $3^{\text {rd }}$ Edition, John Wiley and sons, New York.

Smolin, L. L \& Lawless, K. A. (2003). Becoming literate in the technology age: New responsibilities and tools for teachers. Reading Teacher, 56, 570. Retrieved February 24, 2004, from ERIC database.

Stepp-Greany, J. (2002). Student Perceptions on Language Learning in a Technological Environment: Implications for the New Millennium. Language Learning and Technology, v6 n1. 165-180.

Thornburg, D. (1997). Multimedia encourages new learning styles. [Online] Available form: http://newhorixons.org/strategies/technology/thornburg.htm.

Urdan, T.A. \& Weggen C.C. (2000). Corporate e-learning: Exploring a new frontier. WR Hambrecht.

Table1. E-learning compare to traditional classroom learning methods

\begin{tabular}{|l|l|}
\hline \multicolumn{1}{|c|}{ Traditional Classroom Learning } & \multicolumn{1}{c|}{ E-Learning } \\
\hline Textbooks and reading lists & Electronic content portals, CD-ROM, online resources \\
\hline Chalk and talk & Rich multimedia \& interactive content \\
\hline Class discussion & Inter-classroom collaboration online, chat room \\
\hline On school grounds & Multiple locations (distance learning) \\
\hline Classes are on a fixed schedule & Study on your own schedule \\
\hline Follow a fixed curriculum & Choose exactly what need to study most \\
\hline
\end{tabular}

Table 2. Sample profile

\begin{tabular}{|l|l|}
\hline Number of questionnaires distributed & 100 \\
\hline Number of questionnaires collected back & 80 \\
\hline Response rate & $80 \%$ \\
\hline Number of questionnaires used for analysis & 80 \\
\hline
\end{tabular}


Table 3. Demographic Profile of Respondents

\begin{tabular}{|c|c|c|c|}
\hline Factors & Categories & Frequency & percentage \\
\hline \multirow[t]{2}{*}{ Gender } & Male & 17 & $21.3 \%$ \\
\hline & Female & 63 & $78.7 \%$ \\
\hline \multirow[t]{5}{*}{ Age } & $18-20$ & 11 & $13.8 \%$ \\
\hline & $21-23$ & 47 & $58.8 \%$ \\
\hline & $24-26$ & 9 & $11.3 \%$ \\
\hline & $27-29$ & 5 & $6.3 \%$ \\
\hline & 20 and above & 8 & $10.0 \%$ \\
\hline \multirow[t]{2}{*}{ Students Status } & Full-time & 63 & $78.8 \%$ \\
\hline & Part-time & 17 & $21.3 \%$ \\
\hline \multirow[t]{4}{*}{ Program of Study } & Information technology & 17 & $21.3 \%$ \\
\hline & Business Administration & 36 & $45.0 \%$ \\
\hline & Humanities and Social Science & 23 & $28.8 \%$ \\
\hline & Graduate Studies & 4 & $5.0 \%$ \\
\hline \multirow[t]{3}{*}{ Level of Education } & Diploma & 17 & $21.3 \%$ \\
\hline & Advanced/Higher/Graduate Diploma & 3 & $3.8 \%$ \\
\hline & Bachelor's Degree & 60 & $75.0 \%$ \\
\hline \multirow[t]{3}{*}{ Race } & Malay & 37 & $46.3 \%$ \\
\hline & Chinese & 13 & $16.3 \%$ \\
\hline & Indian & 30 & $37.5 \%$ \\
\hline \multirow[t]{3}{*}{ Marital Status } & Single & 71 & $88.8 \%$ \\
\hline & Living Together & 4 & $5.0 \%$ \\
\hline & Married & 5 & $6.3 \%$ \\
\hline \multirow[t]{2}{*}{$\begin{array}{ll}\text { Are you currently } \\
\text { Employed }\end{array}$} & Yes & 22 & $27.5 \%$ \\
\hline & No & 58 & $72.5 \%$ \\
\hline
\end{tabular}

Table 4. Result of One-way ANOVA analysis

\begin{tabular}{|l|l|l|}
\hline Factors & F & Sig. \\
\hline Age & 3.001 & 0.033 \\
\hline Program of Study & 2.124 & 0.043 \\
\hline Level of Education & 3.246 & 0.025 \\
\hline Race & 1.244 & 0.113 \\
\hline Marital Status & 0.640 & 0.530 \\
\hline
\end{tabular}

